\title{
Identification of the ground movements caused by mining-induced seismicity with the satellite interferometry
}

\author{
Ryszard Hejmanowski, Wojciech T. Witkowski, Artur Guzy, and Agnieszka Malinowska \\ Faculty of Mining Surveying and Environmental Engineering, \\ AGH University of Science and Technology, Cracow, 39-059, Poland
}

Correspondence: Agnieszka Malinowska (amalin@agh.edu.pl)

Published: 22 April 2020

\begin{abstract}
The assessment of the impact of mining-induced seismicity on the natural environment and infrastructure is often limited to the analysis of terrain surface vibrations. However, similar seismic phenomena, like earthquakes, may also imply dislocations and deformations of the rock mass. Such ground movements may occur in areas which are not directly under the influence of the mining. The study of the displacement field caused by mining-induced seismicity is usually carried out with the use of geodetic methods. Classical geodetic measurements provide discrete information about observed ground movements. As a result, they generally do not provide spatially and temporally relevant estimates of the total range and values of ground movements for specific periods of interest. Moreover, mining-induced seismicity causes a severe threat to buildings. That is why, regarding the complexity of the mechanism of occurrence of mining-induced seismicity and their impact on ground movements, this problem remains a substantial research issue. The presented research aimed to analyse the ground movements caused by mining-induced seismicity. The ground displacements were established based on data from Sentinel-1 satellites applying differential interferometric synthetic aperture radar (DInSAR). The results of the investigation in the copper mining area of the Lower Silesia region of Poland revealed that the observed subsidence caused by mining-induced seismicity usually has a shape of a regular ellipse. The radius of these ground movements does not exceed approximately $2-3 \mathrm{~km}$ from the mining-induced tremor's epicenter, and the total subsidence reaches ca. $10-20 \mathrm{~cm}$. More than $50 \%$ of the total subsidence is observed on the surface within a few days after the mining tremor occurrence. Furthermore, the deformations of the surface occur when the energy of mining-induced tremor reaches values of the order of $10^{5} \mathrm{~J}$ or higher. The presented research can contribute to better identification and evaluation of the mechanism of the rock mass deformation process caused by mining-induced seismicity. In addition, the use of satellite radar interferometry improves the quality of monitoring of these dynamic phenomena significantly. The data retrieved using this method allow for quasi-continuous monitoring of the local subsidence bowls caused by mining-induced seismicity.
\end{abstract}

\section{Introduction}

Several dozens of mining-induced earthquakes occur in Poland every year. A few of them exceed the magnitude $M_{\mathrm{w}}=3.5$. These earthquakes are related to changes in stress in the earth's crust as a result of mining. They are characterized by high seismic energy, low frequencies of the main phase of vibrations and high intensity of vibrations in a larger area. Impact of mining-induced earthquakes is usually a significant inconvenience for people living in areas at risk. Earthquakes of this type may even cause structural damage to infrastructure.

The seismic intensity assessment is currently based on specialized empirical scales. One such scale is GSI-2004, which was developed for the local conditions of Legnica-Glogow Copper Ore District (LGCD), Poland (Fig. 1).

Degrees of seismic intensity are determined based on the horizontal amplitudes of earth vibration speed PGV and the 
Table 1. Sentinel-1 images used in the research (Witkowski, 2019).

\begin{tabular}{lllllrc}
\hline $\begin{array}{l}\text { No. } \\
\text { interferogram }\end{array}$ & $\begin{array}{l}\text { Master } \\
\text { image }\end{array}$ & $\begin{array}{l}\text { Slave } \\
\text { image }\end{array}$ & Track & Orbit & $\begin{array}{r}\text { Perpendicular } \\
\text { baseline [m] }\end{array}$ & $\begin{array}{c}\text { No. } \\
\text { interferogram }\end{array}$ \\
\hline 1. & 20 Nov 2017 & 26 Nov 2017 & 22 & Descending & 84 & 1. \\
2. & 23 Nov 2017 & 29 Nov 2017 & 73 & Ascending & 40 & 2. \\
3. & 26 Nov 2017 & 2 Dec 2017 & 22 & Descending & 62 & 3. \\
4. & 29 Nov 2017 & 5 Dec 2017 & 73 & Ascending & 108 & 4. \\
5. & 2 Dec 2017 & 8 Dec 2017 & 22 & Descending & 45 & 5. \\
6. & 5 Dec 2017 & 11 Dec 2017 & 73 & Ascending & 137 & 6. \\
7. & 8 Dec 2017 & 14 Dec 2017 & 22 & Descending & 89 & 7. \\
8. & 11 Dec 2017 & 17 Dec 2017 & 73 & Ascending & 143 & 8. \\
\hline
\end{tabular}

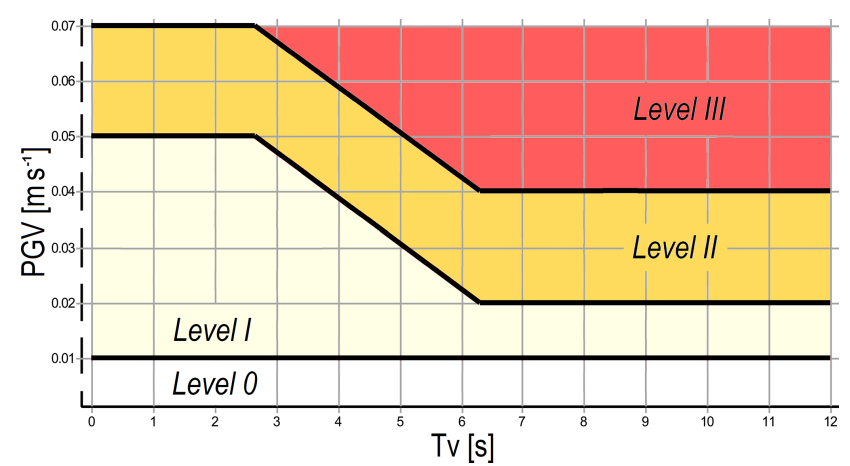

Figure 1. GSI-2004 seismic intensity scale. Degrees of seismic intensity (Level 0-III) are shown as a function of the earth vibration speed (PGV) and the duration of the main vibration phase (TV) (after Wodyński and Lasocki, 2004).

duration of the main vibration phase. Each degree of intensity has been assigned specific effects in the construction works (Wodyński and Lasocki, 2004; Szczerbowski and Jura, 2015; Zembaty et al., 2015; Chen et al., 2007; El Gharbawi and Tamura, 2015; Malinowska et al., 2018). Therefore, the assessment of potential damage in surface development and technical infrastructure is mainly related to determining the map of the PGV ground vibration distribution. However, the occurrence of high-energy earthquakes may also imply subsidence trough.

This aspect is not considered when assessing the effects of the occurrence of these phenomena.

The objective of the proposed research was to determine the total area, which was under the influence of negative impacts caused by the occurrence of a high-energy mininginduced earthquake. These works were carried out based on the determination of the seismic intensity map, coupled with the determination of land subsidence.

\section{Study area}

The study area is located in the Lower Silesia region (a part of the Fore-Sudetic Monocline, Fig. 2). The Fore-Sudetic
Block is composed of metamorphic rocks and volcanogenicsedimentary beds (Central Geological Database, 2019). In that area, a copper deposit is located at the base of Zechstein formations. The thickness of ore layers varies from 0.1 to $15.0 \mathrm{~m}$. Polish copper ore mines belonging to the international copper mining-metallurgic company KGHM have operated copper ore seam mining since 1968. Tectonic recognition of faults of a large stratigraphic throw in the area of the KGHM mines reveals that the majority of faults are NW-SE oriented with an NWW-SEE and NNW-SSE deviation (Salski, 1996; Butra and Kudełko, 2011). The dominant system of faults in the mining area coincides with the fault zone of Ruda Glowna and Glowny Lubin.

\section{Research methodology}

The ground movements were investigated with the use of Sentinel-1 synthetic aperture radar data. These acquisitions were obtained from descending and ascending orbits (Table 1). The ground surface subsidence was determined using DInSAR. Terrain surface movements were analysed for more than four weeks. In total, eight $6 \mathrm{~d}$ interferograms were generated, from which it was possible to study line-ofsight (LOS) movements. The vertical component of surface movement (subsidence) was computed from the LOS movements based on the look angles of the Sentinel-1A, 1-B satellite data acquisitions.

Determination of the amplitude distribution of vibration velocity was based on empirical formulas. The influence of seismic energy, hypocentral distance, and amplitude of 15 vibration on amplitude values of PGV was considered. The input data for the calculations were obtained from the ISEPOS system (Table 2). The map of seismic intensity on the surface environment according to the GSI-2004 scale was determined. Finally, the maps of total subsidence and seismic intensity zones were obtained by interpolating the values of vertical movements of the terrain surface and the values of ground vibration speed PGV (Fig. 3). 


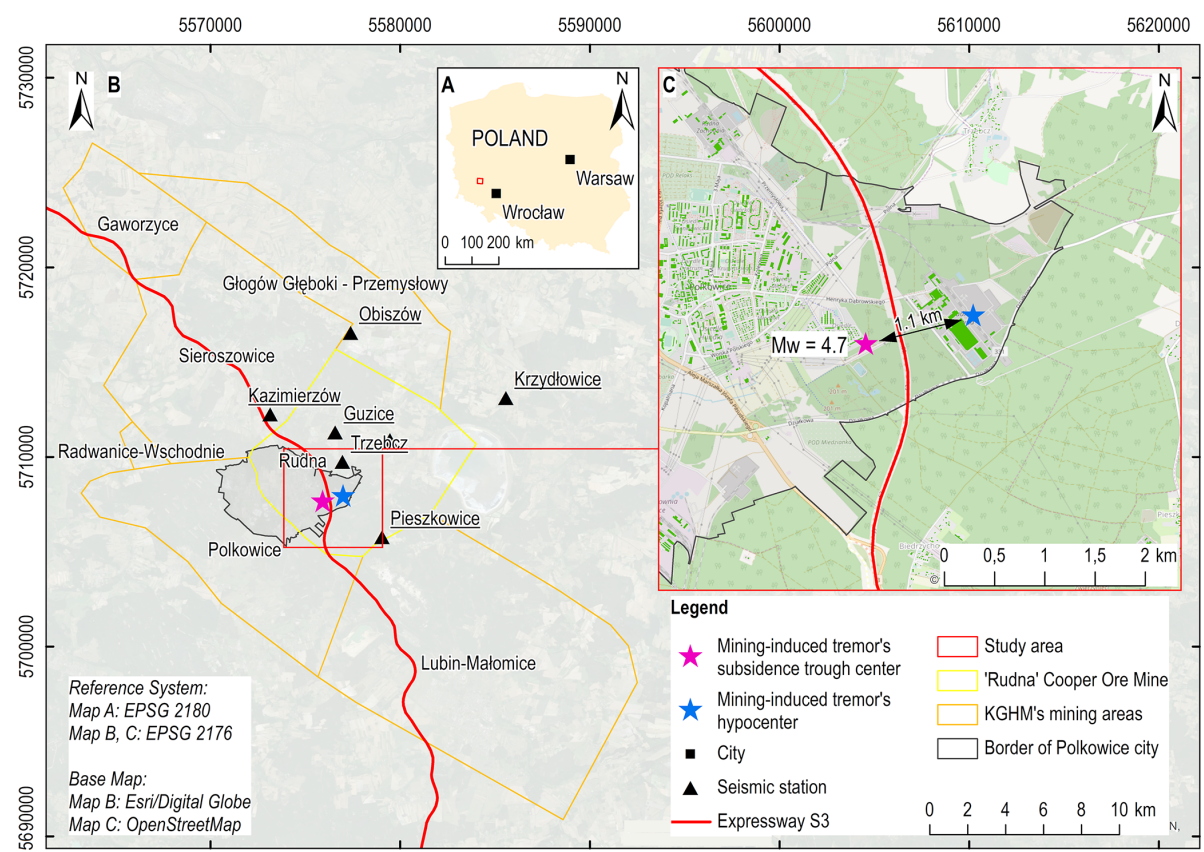

Figure 2. Study area (@ OpenStreetMap contributors 2020. Distributed under a Creative Commons BY-SA License).

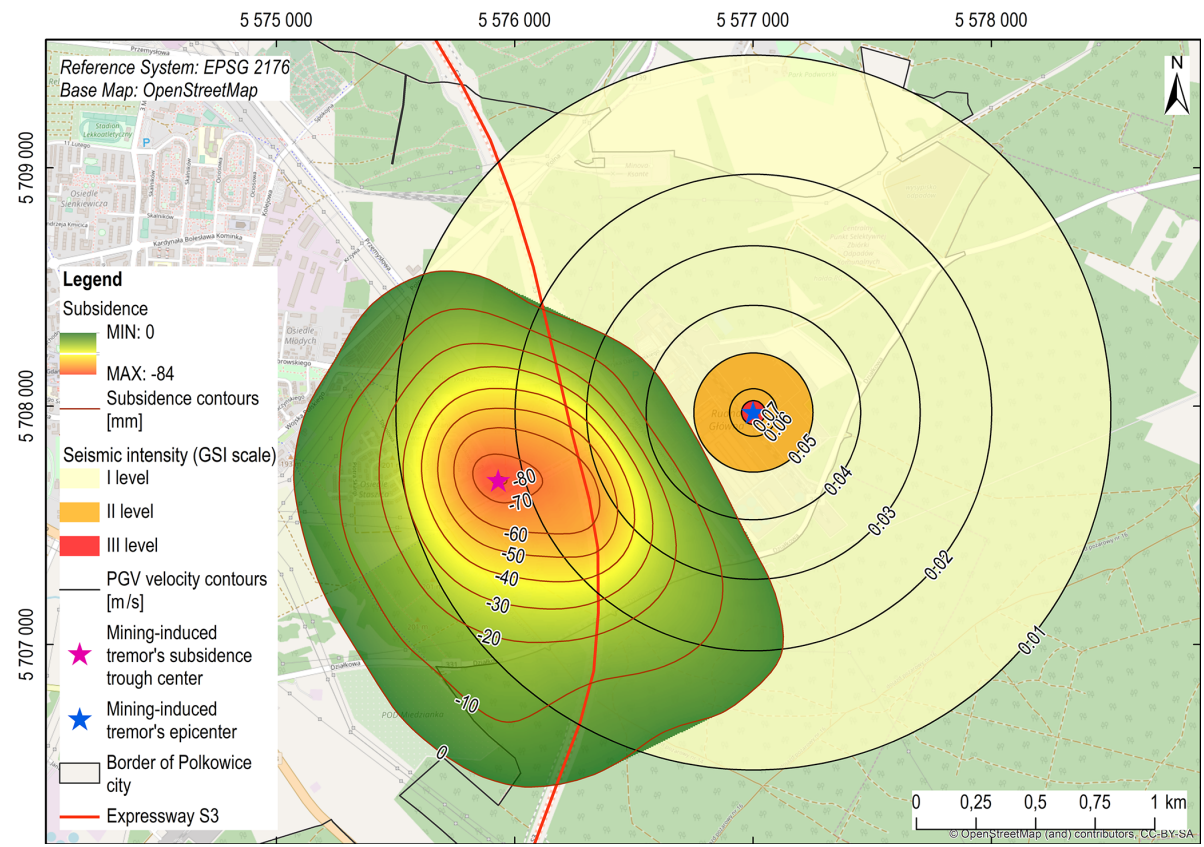

Figure 3. Map of land subsidence and seismic intensity zones resulted from mining-induced tremor occurring at 7 December 2017 (@ OpenStreetMap contributors 2020. Distributed under a Creative Commons BY-SA License).

\section{Results discussion}

Maximal vertical displacements generated through the interpolation reached $-84 \mathrm{~mm}$. The total area of subsidence caused by the earthquake reached about $2 \mathrm{~km}^{2}$ with a subsidence volume of approximately $38000 \mathrm{~m}^{3}$, and a spatial dimension of ca. $1.2-2.0 \mathrm{~km}$ (Fig. 3).
The analysed mining-induced earthquake caused ground surface vibrations with values as much as $0.07 \mathrm{~cm} \mathrm{~s}^{-1}$. These values are within the range of three seismic-intensity-zones: I-III, where the isoline defining the lower boundary of zone I is characterized by a radius of approximately $1.5 \mathrm{~km}$ from the epicenter of the earthquake. Although the most extensive area is occupied by zone I, in which vibrations are strongly 
Table 2. IS-EPOS data on analyzed seismic constraints. Seismic intensity is defined based on peak ground acceleration (PGA), duration of peak ground acceleration ( $\left.t_{\mathrm{PGA}}\right)$, peak ground velocity (PGV) and duration of peak ground velocity $\left(t_{\mathrm{PGV}}\right)(\mathrm{Guzy}, 2019)$.

\begin{tabular}{lccrrccccr}
\hline $\begin{array}{l}\text { Seismic } \\
\text { station }\end{array}$ & $\begin{array}{r}\text { Lat } \\
{\left[^{\circ}\right]}\end{array}$ & $\begin{array}{c}\text { Lon } \\
\left.{ }^{\circ}\right]\end{array}$ & $\begin{array}{r}\text { Elevation } \\
{[\mathrm{m}]}\end{array}$ & $\begin{array}{r}\text { Epicenter } \\
\text { distance } \\
{[\mathrm{m}]}\end{array}$ & $\begin{array}{c}\text { PGA } \\
{\left[\mathrm{m} \mathrm{s}^{-2}\right]}\end{array}$ & $\begin{array}{c}t_{\mathrm{PGA}} \\
{[\mathrm{s}]}\end{array}$ & $\begin{array}{c}\text { PGV } \\
{\left[\mathrm{cm} \mathrm{s}^{-1}\right]}\end{array}$ & $\begin{array}{r}t_{\mathrm{PGV}} \\
{[\mathrm{s}]}\end{array}$ & $\begin{array}{r}\text { GSI } \\
\text { scale }\end{array}$ \\
\hline Dábrowa & 51.500 & 16.140 & 145 & 20624 & 0.203 & 0.64 & 0.989 & 0.69 & $0 / \mathrm{I}$ \\
Guzice & 51.531 & 16.103 & 124 & 3353 & 0.403 & 0.88 & 0.781 & 0.87 & 0 \\
Kazimierzów & 51.539 & 16.054 & 136 & 5757 & 0.098 & 1.54 & 0.568 & 1.45 & 0 \\
Komorniki & 51.527 & 16.145 & 136 & 3822 & 0.110 & 1.11 & 0.810 & 1.18 & 0 \\
Krzydłowice & 51.545 & 16.233 & 95 & 10001 & 0.023 & 5.69 & 0.177 & 5.61 & 0 \\
Obiszów & 51.577 & 16.116 & 118 & 8576 & 0.042 & 3.28 & 0.357 & 3.23 & 0 \\
Pieszkowice & 51.481 & 16.138 & 194 & 3006 & 0.196 & 2.57 & 0.907 & 2.59 & 0 \\
Trzebcz & 51.516 & 16.108 & 143 & 1774 & 0.430 & 0.78 & 1.853 & 0.78 & $\mathrm{I}$ \\
\hline
\end{tabular}

felt by people inside buildings, vibrations with such values do not cause substantial damage to the surface infrastructure. Intensification of existing cracks in infrastructure facilities or damage to finishing elements can be noted only in the second and third zones, the total area of which is approx. $1.8 \mathrm{~km}^{2}$. Zone III, where single damage to structural elements may occur, includes a small area with a radius of approximately $100 \mathrm{~m}$ from the epicenter of the mining-induced earthquake. The area encompassed both by the seismic-intensity-zones and subsidence was about $4.7 \mathrm{~km}^{2}$.

\section{Conclusions}

Coupled InSAR and IS-EPOS data substantially help to detect ground surface movements caused by mining-induced earthquakes. The area of impact of mining-induced earthquake includes not only the regions where the vibration values of the terrain surface are determined (the procedure used presently to determine the area of impact) but also the area affected by land subsidence. As seen in Fig. 3, the spatial distribution of these regions may not show an exact correlation. For example, in the case of subsidence reaching several $\mathrm{cm}$ occurred beyond the boundary of zone I (Fig. 3). Considering the millimetre accuracy of the measured land subsidence and the lower accuracy of the earthquake epicenter determination, the actual area of impact of earthquake perhaps could include the area of observed land subsidence.

Data availability. All data used in this research are freely and fully accessible to all users via the Copernicus Programme and the European Plate Observing System services. Detailed guidelines on data availability are accessible on the following websites: http://www. esa.int/ (Witkowski, 2019) and https://www.epos-ip.org/ (Guzy, 2019).

Author contributions. RH was responsible for research conceptualization, project administration and supervision. WW carried out the research in terms of methodology, he was responsible for data investigation, performing computations and validation of research results. AG cooperated with WW during research investigation and validation, he also prepared research visualisation and wrote the original draft. AM worked with RH in terms of conceptualization, project administration and research supervision.

Competing interests. The authors declare that they have no conflict of interest.

Special issue statement. This article is part of the special issue "TISOLS: the Tenth International Symposium On Land Subsidence - living with subsidence". It is a result of the Tenth International Symposium on Land Subsidence, Delft, the Netherlands, 17-21 May 2021.

Financial support. This research has been supported by the AGH University of Science and Technology in Cracow (grant no. 16.16.150.545).

\section{References}

Butra, J. and Kudełko, J.: Rockburst hazard evaluation and prevention methods in Polish copper mines, Cuprum, 61, 5-20, 2011.

Central Geological Database, Polish Geological Institute, National Research Institute, available at: http://baza.pgi.gov.pl/, last access: 1 January 2019.

Chen, J. L., Wilson, C. R., Tapley, B. D., and Grand, S.: GRACE detects coseismic and postseismic deformation from the Sumatra-Andaman earthquake, Geophys. Res. Lett., 34, L13302, https://doi.org/10.1029/2007GL030356, 2007.

El Gharbawi, T. and Tamura, M.: Coseismic and postseismic deformation estimation of the 2011 Tohoku earthquake in Kanto Region, Japan, using InSAR time series analysis and GPS, Remote Sens. Environ., 168, 374-387, https://doi.org/10.1016/j.rse.2015.07.016, 2015.

Guzy, A.: contains modified European Plate Observing System (EPOS) data 2017, processed by EPOS, 2019. 
Malinowska, A. A., Witkowski, W. T., Guzy, A., and Hejmanowski, R.: Mapping ground movements caused by mining-induced earthquakes applying satellite radar interferometry, Eng. Geol., 246, 402-411, https://doi.org/10.1016/j.enggeo.2018.10.013, 2018.

Salski, W.: The tectonics of the deposit, in: Monografia KGHM Polska, edited by: Miedź, S. A., Profil, Kraków, 1996.

Szczerbowski, Z. and Jura, J.: Mining induced seismic event and surface deformation monitored by GPS permanent stations, Ac. Geodynynam. Geomater., 12, 237-248, https://doi.org/10.13168/AGG.2015.0023, 2015.
Witkowski, W. T.: contains modified Copernicus Sentinel data 2017, processed by ESA, 2019.

Wodyński, A. and Lasocki, S.: Assessment of mining tremor influence on the technical wear of building, Ac. Geodynam. Geomater., 1, 187-194, 2004.

Zembaty, Z., Kokot, S., Bozzoni, F., Scandella, L., Lai, C. G., Kuś, J., and Bobra, P.: A system to mitigate deep mine tremor effects in the design of civil infrastructure, Int. J. Rock Mech. Min. Sci., 74, 81-90, https://doi.org/10.1016/j.ijrmms.2015.01.004, 2015. 